\title{
Peculiarities of topical therapy in pediatric psoriasis
}

\author{
Particularitățile terapiei topice în psoriazisul pediatric \\ Ana Maria Alexandra STĂNESCU ${ }^{1}$, Vlad DIMA², loana Veronica GRĂJDEANU ${ }^{1}$, Mira FLOREA, \\ Anca Angela SIMIONESCU ${ }^{4,5}$
}

${ }^{1}$ Disciplina Medicină de familie, Universitatea de Medicină și Farmacie „Carol Davila“, București, România

${ }^{2}$ Departamentul de Neonatologie, Spitalul Clinic Filantropia, București, România

${ }^{3}$ Disciplina Medicină de familie, Universitatea de Medicină și Farmacie „Iuliu Hațieganu“,

Cluj-Napoca, România

${ }^{4}$ Departamentul Obstetrică-Ginecologie, Spitalul Clinic Filantropia, București, România

${ }^{5}$ Disciplina Obstetrică-Ginecologie, Universitatea de Medicină și Farmacie „Carol Davila",

București, România

\begin{abstract}
In children and adolescents, psoriasis affects between $0.5 \%$ and $1.2 \%$ of the population. Currently, at least 80 chromosomal loci have been discovered that are significantly linked to psoriasis, and some of these loci are mainly linked to the onset of psoriasis in childhood. Pediatric psoriasis can be more difficult to diagnose due to an easier course of the disease, with smaller and thinner plaques, which are less scalable and with atypical manifestations. First-line therapy in psoriasis in both children and adults is represented by topical therapy. Treatment options for psoriasis in children and adolescents are largely off-label, with little data available on efficacy and safety.
\end{abstract}

Keywords: psoriasis, pediatrics, topical therapy

\section{REZUMAT}

La copii și adolescenți, psoriazisul afectează între 0,5\% și 1,2\% din populație. În prezent, au fost descoperite cel puțin 80 de loci cromozomiali care sunt legați în mod semnificativ de psoriazis, iar unii dintre acești loci sunt legați în special de debutul psoriazisului în copilărie. Psoriazisul pediatric poate fi mai dificil de diagnosticat din cauza unui curs al bolii mai ușor, cu plăci mai mici și mai subțiri, care sunt mai puțin scalabile și cu manifestări atipice. Terapia de primă linie în psoriazis, atât la copii, cât și la adulți, este reprezentată de terapia topică. Opțiunile de tratament pentru psoriazis la copii și adolescenți sunt în mare parte off-label, cu puține date disponibile despre eficacitate și siguranță.

Cuvinte cheie: psoriazis, pediatrie, terapie topică 


\section{INTRODUCERE}

Psoriazisul este o boală cronică inflamatorie cutanată care afectează 2-3\% din populația adultă, fără predilecție către bărbați sau femei (1). La copii și adolescenți, afectează între 0,5\% și 1,2\% (2). Debutul bolii survine între 16-22 ani și 57-60 ani, iar aproximativ o treime dintre pacienți au avut deja debutul bolii înainte de vârsta de 16 ani, cu o vârstă medie de 8-11 ani (3).

Patogeneza psoriazisului este complexă și este cauzată de o interacțiune la nivel cutanat, sistemul imunitar, precum și de factori genetici și de mediu. La nivel celular, este o boală inflamatorie mediată de celulele T caracterizată prin hiperproliferare keratinocitară, proliferare endotelială vasculară, precum și infiltrarea celulară inflamatorie a dermei și epidermei, în care sunt implicate celulele Th17 și citokinele interleukină (IL-17 și IL-23) $(4,5)$.

În prezent, au fost descoperite cel puțin 80 de loci cromozomiali care sunt legați în mod semnificativ de psoriazis, iar unii dintre acești loci sunt legați în special de debutul psoriazis în copilărie (6). Rata concordanței este crescută de opt ori la gemenii monozigoți și de patru ori la gemenii dizigoți (7).

Cei mai importanți factori de mediu declanșatori ai psoriazisului la copii sunt stresul mental, traumatismele fizice (fenomenul Köbner) și infecția căilor respiratorii superioare cauzată de streptococi (8).

Psoriazisul pediatric poate fi mai dificil de diagnosticat din cauza unui curs al bolii mai ușor, cu plăci mai mici și mai subțiri, care sunt mai puțin scalabile și cu manifestări atipice. Diagnosticul diferențial al psoriazisului pediatric, printre altele, se face cu dermatita atopică, dermatita seboreică și infecțiile fungice (9).

Severitatea psoriazisului la copii în general este măsurată utilizând scorul PASI, cu toate aceste trebuie avut în vedere faptul că scorul PASI a fost dezvoltat inițial pentru psoriazisul la adult și poate să aibă limitări la copiii mici deoarece proporțiile corpului în acest grup de pacienți sunt destul de diferite în comparație cu adulții (10).

Tratamentul psoriazisului pediatric se bazează pe aceleași principii ca la adulți, însă omologarea terapiei pediatrice nu este întotdeauna realizată. Acest lucru duce ca experții în domeniul sănătății să utilizeze eficacitatea și efectele adverse ale terapiilor actuale cu ajutorul seriilor de cazuri, în funcție de opiniile experților sau de experiența siguranței și eficacității medicamentelor dobândite în studiile clinice care investighează alte tulburări pediatrice.

Terapia de primă linie în psoriazis, atât la copii, cât și la adulți, este reprezentată de terapia topică. În cazul copiilor, se ridică problema aprobării pentru uzul pediatric, deoarece nu toate terapiile topice au aprobare pentru utilizare în pediatrie (11). Agenții topici utilizați în terapia psoriazisului sunt de tipul creme, unguente, spume, geluri și loțiuni (12).

\section{CORTICOSTEROIZI TOPICI}

Corticosteroizii topici reprezintă terapia cel mai des utilizată, indiferent de grupa de vârstă. Corticosteroizi topici cu potență mică până la medie sunt utilizați în general în cazul leziunilor faciale, flexurale și genitale, în timp ce corticosteroizii topici cu potență mare și foarte mare în zonele cu piele groasă, cum ar fi palmele și tălpile.

Studiile au arătat că crema de halobetasol 0,05\% și emulsia de propionat de clobetasol $0,05 \%$ sunt eficiente în psoriazisul pe plăci pediatric, iar efectele secundare raportate au fost relativ ușoare în perioada de tratament de 2 săptămâni, fiind raportate cel mai frecvent senzația de arsură la locul de aplicare sau atrofia pielii $(13,14,15)$.

Corticosteroizii trebuie utilizați cu precauție, utilizare intermitentă sau prin rotație pentru a limita posibilele efecte secundare, care la adulți sunt reprezentate de atrofie, telangiectaziile, dermatita acneiformă, tahifilaxia, dermatita periorală, hipertricoza și, mai rar, suprimarea axului hipotalamic-hipofizar-suprarenal (16).

\section{ANALOGI AI VITAMINEI D}

Analogii vitaminei $D$ și analogii vitaminei $D$ în combinație cu corticosteroizi topici reprezintă o alternativă topică.

Studiile care au urmărit calcipotriol administrat local și calcitriol au arătat eficacitate la pacienții cu psoriazis pediatric cu efecte secundare ușoare. Efectele secundare raportate cel mai frecvent în urma utilizării analogilor vitaminei $D$ au fost iritația locală și pruritul, fiind necesară evitarea aplicării pe zonele cu pielea mai subțire (fața, zonele genitale și flexurale) (17). Dintre formele analogilor vitaminei $D$, unguentul cu calcipotriol pare să fie mai iritant decât unguentul cu calcitriol, iar absorbția sistemică a vitaminei $D$ și creșterea nivelului de calciu sunt puțin probabile dacă tratamentul este utilizat corespunzător $(12,18)$.

Analogii vitaminei $D$ nu sunt recomandați copiilor cu vârsta sub 2 ani, iar utilizarea până la $45 \mathrm{~g} / \mathrm{m}^{2} /$ săptămână la copii și adolescenți cu psoriazis nu pare să influențeze nivelul de calciu la copiii de la 3 la 14 ani $(12,19)$.

În practică, este utilizată și combinația analogilor de vitamina D cu corticosteroizi topici (calcipotriol și betametazonă dipropionat), ceea ce duce la o complianță mai mare a pacientului la tratament, nemaifiind necesară aplicarea lor separată (20). 
Administrarea la copii a unguentului cu calcipotriol/ betametazonă dipropionat o dată pe zi timp de 4 săptămâni și 4 zile pe săptămână după aceea, cu o durată medie a tratamentului de 35 săptămâni, a arătat eficiență în primele săptămâni de administrare și, ulterior, o stabilitate a psoriazisului (21).

Un alt studiu a arătat că aplicarea cutanată de dipropionat de calcipotriol/betametazonă o dată pe zi timp de 8 săptămâni la copii cu vârsta cuprinsă între 12 și 17 ani ce aveau psoriazis în plăci moderat până la sever a fost bine tolerată și eficientă (22).

Administrarea de dipropionat de calcipotrienă/betametazonă la copii cu vârsta între 4 și 17 ani la nivelul scalpului a fost eficientă în primele 12 săptămâni de tratament, iar efectul tratamentului a fost menținut 48 de săptămâni după aceea (23).

\section{INHIBITORI AI CALCINEURINEI}

Inhibitori ai calcineurinei care au fost utilizați la adulți, precum tacrolimus $0,03 \%$ sau $0,1 \%$ și pimecrolimus $1 \%$, s-au dovedit a fi eficienți în leziunile psoriazisului de la nivelul feței, organele genitale și zonele de flexie, reprezentând o alternativă bună pentru tratamentul psoriazisului în aceste zone sensibile la efectele adverse pe termen lung în utilizarea topică a steroizilor (24).

La pacienții pediatrici, s-a evidențiat o îmbunătățire semnificativă în primele 30 de zile de utilizare a tacrolimus $0,1 \%$, cu un singur efect advers raportat, reprezentat de prurit $(25,26)$. Pentru pimecrolimus $1 \%$ nu sunt suficiente date care să susțină utilizarea sa în psoriazisul pediatric.

\section{ANTRALIN}

Antralin reprezintă un agent local cu proprietăți antiinflamatorii și antiproliferative și fără absorbție sistemică semnificativă.

Ditranolul cu contact scurt la concentrații mai mari de $0,1 \%-3 \%$, aplicat pentru perioade mai scurte de timp, 10-30 min., își menține eficacitatea cu un risc diminuat de iritație și colorare, fiind o opțiune terapeutică bună în cazul psoriazisului pediatric. Această terapie a demonstrat o eficacitate de $73,2 \%$ la pacienții pediatrici după o administrare medie de 2 luni și o durată medie de remisie de 5,5 luni (27).

Un alt studiu a demonstrat o reducere semnificativă a scorului severității și a indicelui PASI de 69,3\%, iar singurul eveniment advers raportat a fost iritarea pielii (28).

Pe lângă eficacitatea si siguranța utilizării în pediatrie, este necesar de remarcat că ditranolul poate pata hainele și poate provoca iritații cutanate locale, în special atunci când este utilizat la nivel facial, flexural, în psoriazisul eritrodermic sau pustular.

\section{CONCLUZII}

Opțiunile de tratament pentru psoriazis la copii și adolescenți sunt în mare parte off-label, cu puține date disponibile despre eficacitate și siguranță. Majoritatea copiilor și adolescenților au psoriazis în forme ușoare, existând o mare necesitate de studii clinice care să investigheze eficacitatea și siguranța pe termen lung a tratamentelor topice.

Conflict of interest: none declared Financial support: none declared

\section{BIBLIOGRAFIE}

1. Christophers E. Psoriasis - epidemiology and clinical spectrum. Clin Exp Dermatol. 2001 Jun;26(4):314-20.

2. Michalek IM, Loring B, John SM. A systematic review of worldwide epidemiology of psoriasis. J Eur Acad Dermatol Venereol. 2017 Feb;31(2):205-212.

3. Raychaudhuri SP, Gross J. A comparative study of pediatric onset psoriasis with adult onset psoriasis. Pediatr Dermatol. 2000 May-Jun;17(3):174-8.

4. Nestle FO, Kaplan DH, Barker J. Psoriasis. N Engl J Med. 2009 Jul 30;361(5):496-509.

5. Boehncke WH, Schön MP. Psoriasis. Lancet. 2015 Sep 5;386(9997):983-94.

6. Lysell J, Tessma M, Nikamo P, Wahlgren CF, Ståhle M. Clinical characterisation at onset of childhood psoriasis - a cross sectional study in Sweden. Acta Derm Venereol. 2015 Apr;95(4):457-61.
7. Lønnberg AS, Skov L, Skytthe A, Kyvik KO, Pedersen OB, Thomsen SF. Heritability of psoriasis in a large twin sample. $\mathrm{Br} J$ Dermatol. 2013 Aug;169(2):412-6.

8. Blegvad C, Nybo Andersen AM, Groot J, Zachariae C, Barker J, Skov L. Clinical characteristics including cardiovascular and metabolic risk factors in adolescents with psoriasis. J Eur Acad Dermatol Venereol. 2020 Jul;34(7):1516-1523.

9. Mahé E. Childhood psoriasis. Eur J Dermatol. 2016 Dec 1;26(6):537-548.

10. Eisert L, Augustin M, Bach S, Dittmann M, Eiler $\mathrm{R}$, et al. S2k guidelines for the treatment of psoriasis in children and adolescents - Short version part 1. J Dtsch Dermatol Ges. 2019 Aug;17(8):856-870.

11. Sticherling M, Augustin M, Boehncke WH, Christophers E, et al. Therapy of psoriasis in childhood and adolescence - a German expert consensus. J Dtsch Dermatol Ges. 2011 Oct;9(10):815-23.

12. Bhutani T, Kamangar F, Cordoro KM. Management of pediatric psoriasis. Pediatr Ann. 2012 Jan 13;41(1):e1-7.

13. de Jager ME, de Jong EM, van de Kerkhof PC, Seyger MM. Efficacy and safety of treatments for childhood psoriasis: a systematic literature review. J Am Acad Dermatol. 2010 Jun;62(6):1013-30.

14. Kimball AB, Gold MH, Zib B, Davis MW; Clobetasol Propionate Emulsion Formulation Foam Phase III Clinical Study Group. Clobetasol propionate emulsion formulation foam $0.05 \%$ : review of phase II open-label and phase III randomized controlled trials in steroid-responsive dermatoses in adults and adolescents. J Am Acad Dermatol. 2008 Sep;59(3):448-54. 
15. Herz G, Blum G, Yawalkar S. Halobetasol propionate cream by day and halobetasol propionate ointment at night for the treatment of pediatric patients with chronic, localized plaque psoriasis and atopic dermatitis. J Am Acad Dermatol. 1991 Dec;25(6 Pt 2):1166-9.

16. Tollefson MM. Diagnosis and management of psoriasis in children. Pediatr Clin North Am. 2014 Apr;61(2):261-77.

17. Ståhle M, Atakan N, Boehncke WH, Chimenti S, et al. Juvenile psoriasis and its clinical management: a European expert group consensus. J Dtsch Dermatol Ges. 2010 Oct;8(10):812-8.

18. Silverberg NB. Pediatric psoriasis: an update. Ther Clin Risk Manag. 2009; 5:849-56.

19. Oranje AP, Marcoux D, Svensson A, Prendiville $\mathrm{J}$, et al. Topical calcipotriol in childhood psoriasis. J Am Acad Dermatol. 1997 Feb;36(2 Pt 1):203-8.

20. van de Kerkhof PC, Hoffmann V, Anstey A, Barnes $L$, et al. A new scalp formulation of calcipotriol plus betamethasone dipropionate compared with each of its active ingredients in the same vehicle for the treatment of scalp psoriasis: a randomized, double-blind, controlled trial. Br J Dermatol. 2009 Jan;160(1):170-6.

21. van Geel MJ, Mul K, Oostveen AM, van de Kerkhof PC, de Jong EM, Seyger MM. Calcipotriol/betamethasone dipropionate ointment in mild-to-moderate paediatric psoriasis: long-term daily clinical practice data in a prospective cohort. $\mathrm{Br} \mathrm{J}$ Dermatol. 2014 Aug;171(2):363-9.

22. Gooderham M, Debarre JM, Keddy-Grant J, Xu Z, Kurvits M, Goodfield M. Safety and efficacy of calcipotriol plus betamethasone dipropionate gel in the treatment of scalp psoriasis in adolescents 12-17 years of age. Br J Dermatol. 2014 Dec;171(6):1470-7.

23. Oostveen AM, de Jong EM, Donders AR, van de Kerkhof PC, Seyger MM. Treatment of paediatric scalp psoriasis with calcipotriene/betamethasone dipropionate scalp formulation: effectiveness, safety and influence on children's quality of life in daily practice. J Eur Acad Dermatol Venereol. 2015 Jun;29(6):1193-7.
24. Wang C, Lin A. Efficacy of topical calcineurin inhibitors in psoriasis. J Cutan Med Surg. 2014 Jan-Feb;18(1):8-14.

25. Steele JA, Choi C, Kwong PC. Topical tacrolimus in the treatment of inverse psoriasis in children. J Am Acad Dermatol. 2005 Oct:53(4):713-6.

26. Brune A, Miller DW, Lin P, Cotrim-Russi D, Paller AS. Tacrolimus ointment is effective for psoriasis on the face and intertriginous areas in pediatric patients. Pediatr Dermatol. 2007 Jan-Feb;24(1):76-80.

27. de Jager ME, van de Kerkhof PC, de Jong EM, Seyger MM. Dithranol therapy in childhood psoriasis: unjustifiably on the verge of falling into oblivion. Dermatology. 2010;220(4):329-32.

28. Oostveen AM, Beulens CA, van de Kerkhof $P C$, de Jong EM, Seyger MM. The effectiveness and safety of short-contact dithranol therapy in paediatric psoriasis: a prospective comparison of regular day care and day care with telemedicine. $\mathrm{Br} \mathrm{J}$ Dermatol. 2014 Feb;170(2):454-7. 